\title{
An examination of the frequency and severity of injuries and incidents at three levels of professional football
}

\author{
Richard D Hawkins, Colin W Fuller
}

\begin{abstract}
Objective-To assess the risk of injury to professional footballers during European international and English Premier and First Division league matches.

Methods-Videotaped recordings of 29, 49, and 93 matches from the 1996 European Championship, 1996/1997 English Premier season and 1994 to 1997 English First Division seasons respectively were analysed. During each match, several relevant variables, including the number of fouls, injuries, time of incident, player identity, and injury mechanism, were recorded.

Results-Significantly more free kicks were awarded during international matches than during league matches; however, there were no significant differences between the numbers of free kicks awarded over the three First Division seasons assessed. Between 1.7 and $3.0 \%$ of fouls resulted in a player requiring treatment for injury, but only $15-28 \%$ of all injuries resulted from foul play. In all "non-foul" situations, in which injury resulted, at least $60 \%$ still involved player to player contact. No significant differences in injury frequency were observed between playing positions or match halves.

Conclusions-The results equate to a total of 808 players per season from the estimated 2600 players in the four English professional football leagues sustaining a match injury that caused them to miss at least one game. The large number of underlying "non-injury" incidents is identified as the reason for this level of injury rather than a higher ratio of "injury" to "non-injury" incidents in professional football compared with other occupations.

(Br F Sports Med 1998;32:326-332)
\end{abstract}

Centre for Hazard and

Risk Management,

Loughborough

University,

Loughborough, Leics

LE11 3TU, United

Kingdom

R D Hawkins

C W Fuller

Correspondence to:

Dr C W Fuller.

Accepted for publication 27 July 1998 to collect relevant data so that the risks can be quantified and compared with other activities.

To comply with UK health and safety legislation, the risk management process should aim to identify factors that could lead to injury. As the severity of the outcome of any incident is often dependent on chance, the best way to assess the overall levels of risk in any activity is to identify the underlying causes and measure their frequency of occurrence and the severity of injuries resulting from these causes. This stage should then be followed by the development and implementation of control strategies to reduce the magnitude of the risks or eliminate the causes completely. As most injuries in professional football are claimed to occur during competitive games, ${ }^{3} 4$ a major step in the overall risk management process should therefore be quantification of the risks to players during competitive matches. An assessment of the level of this risk at the highest level of competition was undertaken during the 1994 World Cup Finals. ${ }^{5}$ The aim of the current work was to extend the assessment process to a further three levels of professional competition and to compare these results with those obtained previously from the 1994 World Cup.

\section{Methods}

Three levels of professional football were assessed, namely European international, English Premier League, and English First Division. Assessments were made from videotaped recordings of 171 televised matches over a period of three years. These matches comprised 29 of the 31 matches played during the European Championship Finals staged in England during June 1996, 49 matches played in the English Premier League during the 1996/ 1997 season, and 93 matches played in the English First Division during the 1994/1995 (26), 1995/1996 (27) and 1996/1997 (40) seasons.

The criteria used for analysis were the same as those used previously for the 1994 World Cup Finals. ${ }^{5}$ They included: the use of refereeing decisions on free kicks for the specification of incident category - that is, foul and non-foul play; players receiving treatment on or off the pitch for the specification of injury; and three levels of incident severity: "moderate" (the player received treatment and subsequently missed at least the next match), "minor" (the player received treatment but did not miss the next match through injury), and "non-injury" (the referee deemed a foul to have been committed but no player required treatment). 
Table 1 Number of games analysed, free kicks awarded and injuries observed

\begin{tabular}{|c|c|c|c|c|c|}
\hline \multirow[b]{2}{*}{ Level of competition } & \multirow[b]{2}{*}{ Year/ season } & \multirow{2}{*}{$\begin{array}{l}\text { Games } \\
\text { analysed }\end{array}$} & \multirow{2}{*}{$\begin{array}{l}\text { Foul play free } \\
\text { kicks }\end{array}$} & \multicolumn{2}{|c|}{ Player treatments } \\
\hline & & & & Foul & Non-fou \\
\hline World Cup ${ }^{5}$ & 1994 & 44 & 1272 & 33 & 81 \\
\hline European Championship & 1996 & 29 & 1011 & 22 & 58 \\
\hline Premier League & 1996/97 & 49 & 998 & 17 & 100 \\
\hline First Division & $1994 / 95$ & 26 & 571 & 14 & 75 \\
\hline First Division & $1995 / 96$ & 27 & 604 & 22 & 54 \\
\hline First Division & $1996 / 97$ & 40 & 873 & 25 & 77 \\
\hline
\end{tabular}

During the European Championship, reports available through national television, radio, and press provided detailed information which enabled the severity of players' injuries to be determined. For matches in the English Premier and First Division leagues such detailed information was not available on a reliable basis to categorise injury severity so it was not possible to identify moderate and minor injuries in this way; therefore for most of these matches the two levels of injury severity were combined. However, comparable information was available for some matches from club physiotherapists involved in a complementary study, ${ }^{6}$ and this information was used to provide representative data on the severity of players' injuries.

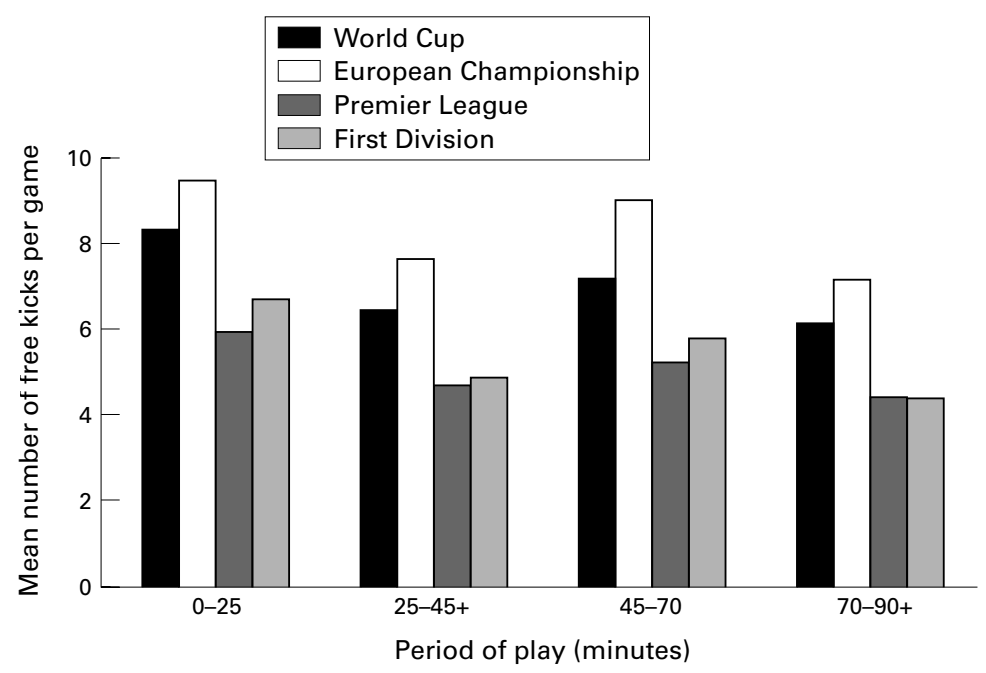

Figure 1 Mean number of free kicks awarded for foul play in each quarter of play.

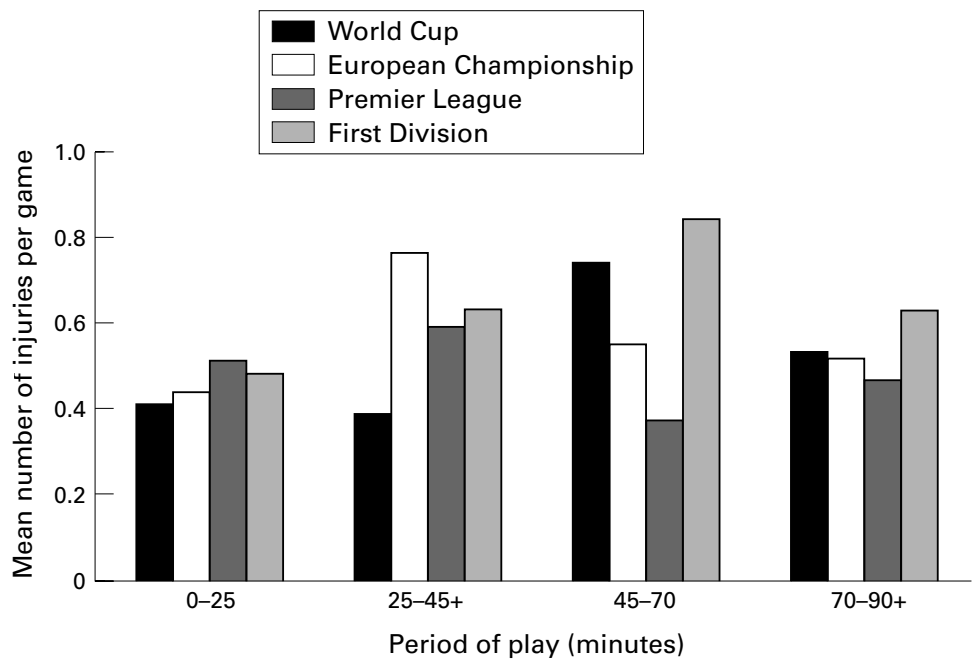

Figure 2 Mean number of all injuries in each quarter of play.
Table 2 Accident ratios: all injuries

\begin{tabular}{lllll}
\hline \multirow{5}{*}{$\begin{array}{l}\text { Incident } \\
\text { severity }\end{array}$} & \multicolumn{4}{l}{ Level of competition } \\
\cline { 2 - 5 } & Wurld & $\begin{array}{l}\text { European } \\
\text { Championship }\end{array}$ & $\begin{array}{l}\text { Premier } \\
\text { League }\end{array}$ & $\begin{array}{l}\text { First } \\
\text { Division }\end{array}$ \\
\hline Moderate & 1 & 1 & 1 & 1 \\
Minor & 5.7 & 5.7 & $5.3^{\star}$ & 4.5 \\
Non-injury & 73 & 82 & 53 & 41 \\
\hline
\end{tabular}

*See text for the calculation of this value.

The numbers of injuries recorded at each competitive level were analysed and assessed in three formats": "accident ratio" (AR), the ratio of the number of injuries at each level of injury severity; "injury incidence rate" (IIR), the percentage likelihood of an individual player receiving treatment for an injury (moderate or minor) during a match; and "injury frequency rate" (IFR), the number of injuries (moderate or minor) per 100000 hours played.

Data were analysed using the Statistical Package for Social Scientists (SPSS Inc, Chicago, Illinois, USA). Student's $t$ test for correlated means was used to examine differences in results obtained between match halves. A one way analysis of variance for correlated means was used to investigate differences between match quarters, the Tukey post-hoc test being used to identify where significant differences occurred. A two way analysis of variance with repeated measures on one factor was used to identify any differences between each competitive level of play, the Scheffe $S$ post-hoc test being used to identify where significant differences occurred. Results are reported as means, and, where differences in results are documented, statistical significance was met at a minimum level of $\mathrm{p}<0.05$.

\section{Results}

Table 1 shows the numbers of games analysed, free kicks awarded for foul play, and player treatments for injury arising from foul and non-foul incidents for each season and/or level of competition. The average numbers of free kicks per game were found to be: World Cup, ${ }^{5}$ 29; European Championship, 35; Premier League, 20; First Division, 22 (table 1). Significantly more free kicks were awarded on average per game during the World Cup and European Championship than during the Premier League and First Division matches, and the 1996 European Championship also produced significantly more free kicks per game than the 1994 World Cup. There were no significant differences between the numbers of free kicks awarded in each of the three First Division seasons analysed. Between 1.7 and $3.0 \%$ of fouls committed actually led to a player requiring treatment, with no significant differences being observed between the four levels of competition (table 1). In addition, no significant correlation was found between the number of free kicks awarded and the number of injuries in matches at any level of competition.

Figure 1 shows the mean number of free kicks awarded for foul play in each quarter of play, and figs 2,3 , and 4 show the mean number of player injuries resulting from all, 


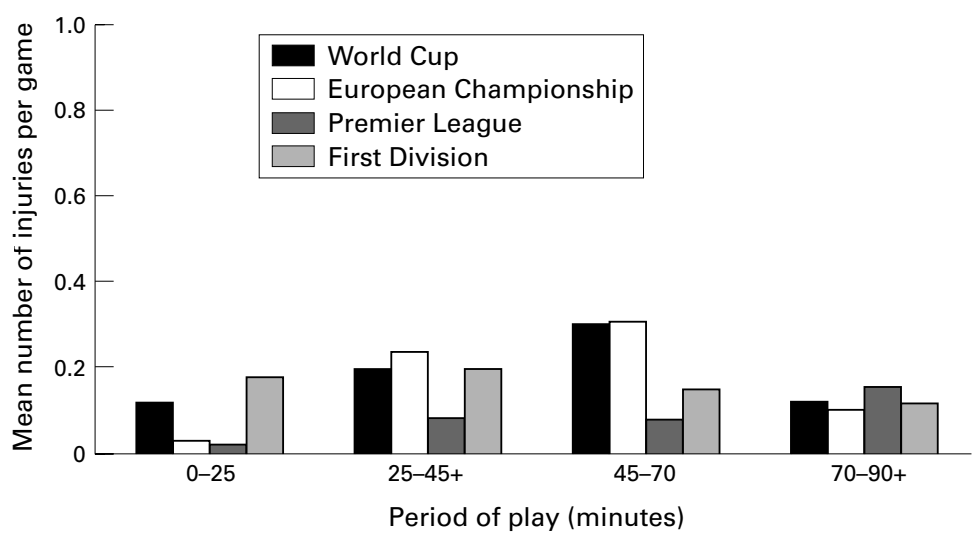

Figure 3 Mean number of injuries resulting from foul play in each quarter of play.

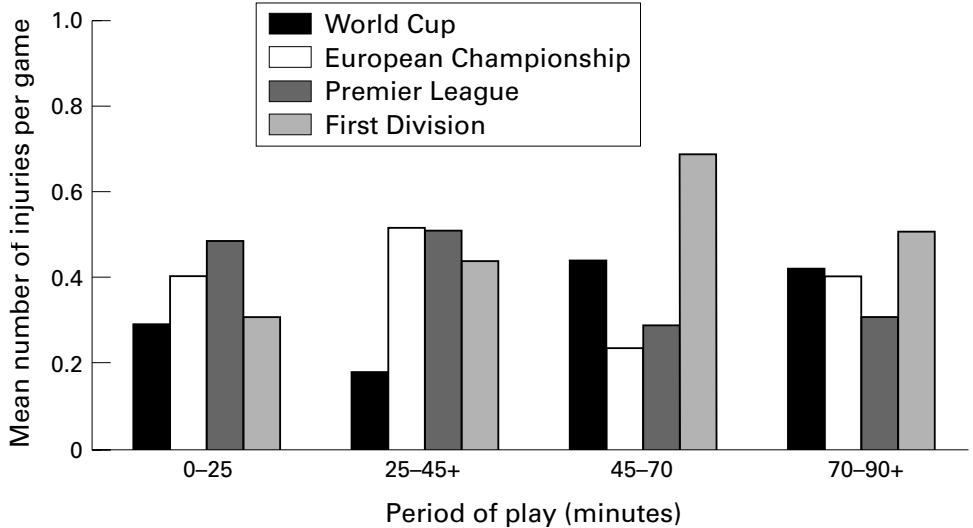

Figure 4 Mean number of injuries resulting from non-foul situations in each quarter of play. minor, and non-injury incidents. For the English Premier and First Division leagues, where it was not possible to distinguish between moderate and minor injuries from media reports, injury data were provided by physiotherapists for teams involved in eight Premier and 21 First Division matches analysed.

\section{All injuries}

A total of 12 moderate injuries, 68 minor injuries, and 989 non-injury incidents were recorded during the 1996 European Championship (table 1). Therefore, for every moderate injury that prevented participation for a minimum of one game, there were 5.7 minor injuries and 82.4 non-injury incidents which could potentially have led to an injury (table 2). A total of 117 moderate plus minor injuries and 981 non-injury incidents were recorded during the 1996/97 Premier League matches; for the 1994-1997 First Division league matches, 267 moderate plus minor injuries and 1987 noninjury incidents were recorded (table 1). For the 29 League matches for which injury data were provided by club physiotherapists, there were no moderate injuries and six minor injuries for the eight Premier League matches and four moderate and 18 minor injuries for the 21 First Division matches. Therefore, by using this ratio of moderate to minor injuries of $1: 4.5$, it was calculated that the overall $\mathrm{AR}$ for the First Division was for every moderate injury there were 4.5 minor injuries and 40.9 non-injury incidents (table 2). As no moderate injuries were reported in the eight Premier matches, it is not possible to derive a direct ratio of moderate to minor injuries; however, the average ratio (1:5.3) observed for the World Cup, European Championship, and First Division has been used to calculate a comparable AR for the Premier League of one moderate injury for every 5.3 minor injuries and 52.8 non-injury incidents (table 2). These results can be further subdivided into two categories: those injuries resulting from foul and those from non-foul incidents.

\section{Injuries resulting from foul situations}

In the European Championship matches, only one incident resulted in a moderate injury, with a further 21 minor injuries incurred from the 1011 fouls recorded. During the tournament three players were treated in the final game of their country, one of whom was substituted. It was assumed in the absence of other information that these players would have been fit if any further games had been played and therefore these injuries were classed as minor. From the 998 fouls recorded during the 49 Premier League matches, 17 resulted in moderate or minor injuries. From the 2048 here to show the ratio of results for moderate,

Table 3 Accident ratios: foul and non-foul situations

\begin{tabular}{|c|c|c|c|c|c|c|c|c|}
\hline \multirow[b]{3}{*}{ Incident severity } & \multicolumn{8}{|c|}{ Level of competition/incident category } \\
\hline & \multicolumn{2}{|c|}{ World Cup ${ }^{5}$} & \multicolumn{2}{|c|}{ European Championship } & \multicolumn{2}{|c|}{ Premier League } & \multicolumn{2}{|c|}{ First Division } \\
\hline & Foul & Non-foul & Foul & Non-foul & Foul & Non-foul & Foul & Non-foul \\
\hline All injuries & 1 & 2.5 & 1 & 2.6 & 1 & 5.9 & 1 & 3.4 \\
\hline Non-injury & 38 & - & 45 & - & 58 & - & 33 & - \\
\hline
\end{tabular}


Table 4 Injury incidence rates (IIR)

\begin{tabular}{|c|c|c|c|c|}
\hline & \multicolumn{4}{|c|}{ Level of competition } \\
\hline & $\begin{array}{l}\text { World } \\
\text { Cup }\end{array}$ & $\begin{array}{l}\text { European } \\
\text { Championship }\end{array}$ & $\begin{array}{l}\text { Premier } \\
\text { League }\end{array}$ & $\begin{array}{l}\text { First } \\
\text { Division }\end{array}$ \\
\hline Matches & 44 & 29 & 49 & 93 \\
\hline Players & 968 & 638 & 1078 & 2046 \\
\hline Injuries & 114 & 80 & 117 & 267 \\
\hline IIR (\%) & 11.8 & 12.5 & 10.9 & 13.0 \\
\hline
\end{tabular}

Table 5 Injury frequency rates per 100000 playing hours for all injuries

\begin{tabular}{|c|c|c|c|c|}
\hline \multirow[b]{2}{*}{$\begin{array}{l}\text { Incident } \\
\text { category }\end{array}$} & \multicolumn{4}{|c|}{ Injury frequency rate } \\
\hline & $\begin{array}{l}\text { World } \\
\text { Cup }\end{array}$ & $\begin{array}{l}\text { European } \\
\text { Championship }\end{array}$ & $\begin{array}{l}\text { Premier } \\
\text { League }\end{array}$ & $\begin{array}{l}\text { First } \\
\text { Division }\end{array}$ \\
\hline Foul & 1992 & 1984 & 946 & 1789 \\
\hline Non-foul & 4888 & 5230 & 5565 & 6041 \\
\hline All & 6880 & 7214 & 6511 & 7830 \\
\hline
\end{tabular}

fouls recorded during the 93 First Division league matches, there were 61 incidents which resulted in moderate or minor injuries. Taking the number of moderate and minor injuries together produces ARs for all injury to non-injury incidents of $1: 45,1: 58$, and $1: 33$ for the European Championship, Premier League and First Division respectively (table 3 ).

Injuries resulting from non-foul situations

Eleven injuries were judged to be at least moderate during the European Championship, with a further 47 minor injuries. Fifteen of the injuries categorised as minor occurred in the final game of the country. During the Premier

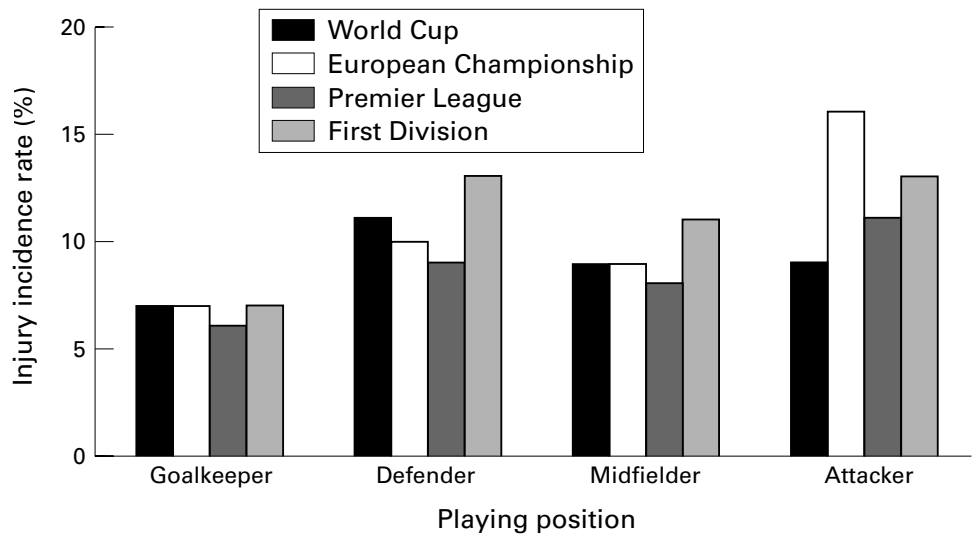

Figure 5 Injury incidence rates as a function of playing position.

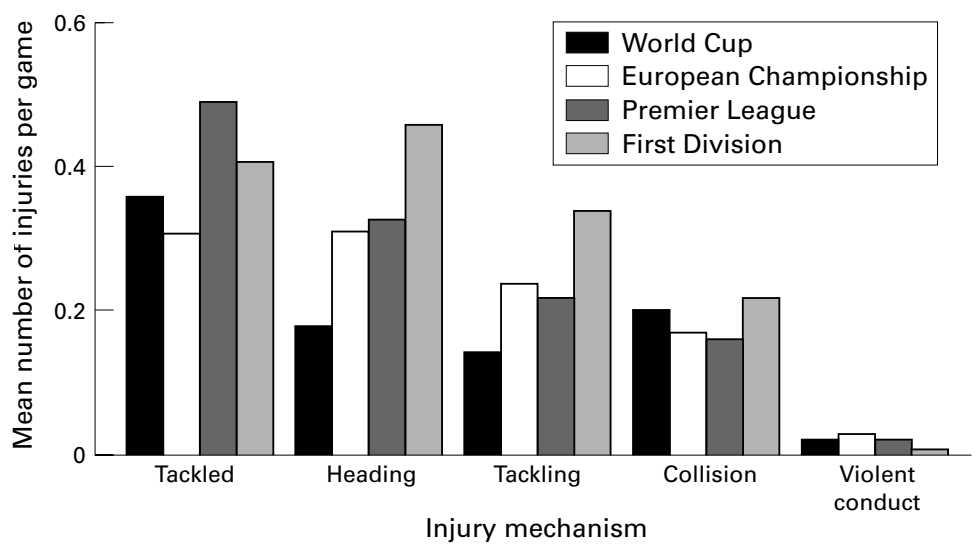

Figure 6 Mechanisms of player to player contact injuries in non-foul situations.
League matches, 100 injuries were judged to be at least moderate or minor, and 206 were judged to be at least moderate or minor during the First Division league matches. By normalising these results on the number of injuries resulting from foul situations at each competitive level, ARs of 2.6, 5.9, and 3.4 were obtained for all injuries resulting from non-foul incidents during the European Championship, Premier League, and First Division matches respectively (table 3 ). The number and nature of the underlying causes of non-foul injuries have not been identified, and therefore these ratio figures are missing from table 3.

\section{INJURY INCIDENCE RATES}

The IIR has been defined previously ${ }^{5}$ as the ratio of the sum of all moderate and minor injuries recorded to the number of players taking part in all the matches analysed, expressed as a percentage. The calculations assumed that 22 players were present at all times during each game. These figures therefore represent the likelihood that any individual player will receive medical treatment as the result of an injury during a match at each level of competition. There were no significant differences in IIRs for the World Cup ${ }^{5}(11.8 \%)$, European Championship (12.5\%), Premier League (10.9\%), and First Division (13.0\%) (table 4). There were also no significant differences in the IIR values as a function of match halves or playing position (fig 5) for the three levels of competition.

\section{INJURY FREQUENCY RATES}

The IFR has been defined previously ${ }^{5}$ as the sum of all moderate and minor injuries recorded during the total player playing time normalised to 100000 playing hours. These values are therefore consistent with criteria used in other working environments for assessing levels of risk. The calculations assumed that there were 100 minutes in each standard game, 130 minutes in games where extra time was played (except in the European Championship final when 105 minutes were played as a result of the golden goal ruling), and that 22 players were involved in each match at all times. This gives total equivalent playing hours of 1109 hours for the 29 European Championship matches, 1797 hours for the 49 Premier League matches, and 3410 hours for the 93 First Division matches assessed. Table 5 shows the IFR values for injuries received in foul, non-foul, and all categories for the European Championship, Premier League, and First Division matches. The overall IFR values in professional football were not found to differ significantly between the four levels of competition, but IFRs were found to be significantly higher in non-foul than in foul situations at all levels of competition.

Table 6 summarises the impact of player to player contact in non-foul situations, and fig 6 shows the mechanisms leading to injury through player to player contact in non-foul situations. 
Table 6 Injury causation in non-foul situations

\begin{tabular}{llll}
\hline & \multicolumn{2}{l}{ Injury causation (\%) } \\
\cline { 2 - 4 } Level of competition & $\begin{array}{l}\text { Player to player } \\
\text { contact }\end{array}$ & $\begin{array}{l}\text { No player to } \\
\text { player contact }\end{array}$ & Not established \\
\hline World Cup $^{5}$ & 49 & 20 & 31 \\
European Championship & 62 & 16 & 22 \\
Premier League & 60 & 15 & 25 \\
First Division - 94/95 & 65 & 15 & 20 \\
First Division - 95/96 & 76 & 13 & 11 \\
First Division - 96/97 & 63 & 20 & 17 \\
\hline
\end{tabular}

\section{Discussion}

This study assesses injury frequency and severity during competitive games at three levels of professional football, namely European international, English Premier, and English First Division, and complements our earlier work covering international football at World level. ${ }^{5}$ The results and conclusions from this work have therefore been compared with the earlier results to present a more complete assessment of incidents and injuries within professional football.

The higher number of free kicks awarded on average during World Cup and European Championship games may be attributable to the specific guidance provided to all referees before these international competitions with the aim of achieving consistency in decision making.

The ratio values for moderate to minor injuries shown in table 2 were used to calculate moderate IFR values from the overall values shown in table 5: 1027, 1077, 1033, and 1424 per 100000 playing hours for the World Cup, European Championship, Premier League, and First Division respectively. These compare with previous results of 2384 for a Scottish Premier League club, ${ }^{9} 1690$ for Swedish senior amateur league teams, ${ }^{10}$ and 940 for international youth (9 to 19 years) teams. ${ }^{11}$ The present results therefore do not support previous reports that injury levels increase with increasing levels of competition, ${ }^{42-14}$ and, within the highest levels of professional football, the levels of risk to players appear to be similar at the present time.

The percentage of injuries resulting from foul situations compared with the total number of injuries recorded (table 1) were calculated to be $29,28,15$, and $23 \%$ for the World Cup, ${ }^{5}$ European Championship, Premier League, and First Division respectively. These results are very similar to those reported previously ${ }^{3215}$ where fouls were found to be responsible for between 19 and $28 \%$ of match injuries. Over $60 \%$ of the injuries resulting from foul situations were found to be sustained while the injured player was being tackled, the free kick being awarded in favour of the injured player in over $97 \%$ of cases at all competitive levels.

The main primary causation factor for injuries resulting from non-foul situations was still found to be player to player contact (table 6). The range of results obtained for the four levels of competition (49-76\%) is consistent with the work of Sandelin et $a l^{4}(52 \%)$ and Hoff and Martin $^{16}(66 \%)$. The apparently lower proportion of injuries from this cause in the World Cup is thought to be because more injuries were defined in the non-contact and nonestablished categories as a consequence of the adverse temperature and humidity conditions in many of those matches. ${ }^{5}$ The main mechanisms leading to these player to player contact injuries were found to be being tackled, heading, and tackling (fig 6). The high number of injuries arising from player to player contacts in non-foul situations has been highlighted previously, ${ }^{5}$ and the results presented here confirm these earlier results. They also support the suggestion that an assessment should be made to ascertain whether minor changes to the laws of the game involving tackling could reduce the number of underlying incidents with the potential to cause injury. Reviews by FIFA before the 1994 and 1998 World Cups have already required referees to be more strict in their judgments on player to player challenges relating to the use of elbows and tackling from behind, and it is expected that these changes will reduce the overall number of injuries.

The results reported here support the findings of Ekstrand and Gillquist ${ }^{17}$ that there are no significant differences in the IIR values for the various playing positions (fig 5). However, it may prove useful in future work, irrespective of a player's designated team role, to document whether injured players were defending or attacking at the time of injury and where they were on the field of play. The results reported here do not support the earlier result obtained during the 1994 World Cup showing that significantly more injuries occur in the second half of matches. ${ }^{5}$ The present findings support the comment made previously that heat stress may have contributed to the increase in injury rates towards the end of games during the 1994 World Cup.

$\mathrm{AR}$ values reported here for football (table 2) compare favourably with those previously reported for other work environments. The Health and Safety Executive ${ }^{18}$ obtained average AR values for the same categories of incident as used in the present study of 1:6.9:189 in four case studies in food, transport, off-shore oil, and hospital work environments. It is not surprising that the figures obtained for the non-injury component are smaller in the present study as the underlying causes of the non-foul injuries could not be identified and their numbers are not included. It is therefore the high number of underlying incidents, each with the potential to cause injury, which brings about the high number of injuries compared with other work environments, ${ }^{19}$ rather than any inherent propensity for a higher proportion of more serious injuries in professional football. A reduction in the number of underlying incidents, in particular those resulting in non-foul injuries, should therefore reduce the overall number of injuries. Player awareness of injury prevention strategies-for example, warm up and cool down, nutrition, and flexibility and strength training-which could reduce the number of non-foul injuries has been reported as being generally low. ${ }^{20}$

The results reported here indicate that, on average, there is a $12.1 \%$ chance of any individual player requiring medical treatment 
during a match, with $14.9 \%$ of these treatments resulting in a player missing at least one match through the injury. In England, for the 20 teams in the Premier League and the 24 teams in the First, Second, and Third Divisions, these results equate to a total of 808 out of an estimated 2600 players per season receiving a match injury causing them to miss at least one game.

Match analysis has provided a simple procedure for assessing the frequency and severity of incidents and injuries at four levels of professional football. The data obtained from this approach can be used by administrators, managers, and players who have to make decisions that determine the acceptability of risk levels within football. This risk assessment approach can be readily adapted for use in many other sports - for example, rugby, basketball, ice hockey, and cricket. The approach adopted here does not, however, differentiate between acute and chronic injuries or injuries resulting in a player missing a single game or a complete season; however, information on injury severity has been reported in a complementary study, ${ }^{6}$ and the importance of structured health surveillance programmes in reducing the incidence of chronic injuries has been reported previously. ${ }^{21}$ In addition, this approach only identifies the broad categories of underlying causes of the players' injuries: a detailed assessment of this area is currently in progress using a human factors approach to assess causes of industrial accidents. ${ }^{22}$

1 Henderson M. Living with risk. London: British Medical Association, 1987.
2 Fuller CW. Implications of health and safety legislation for the professional sportsperson. Br f Sports Med 1995;29:5-9.

3 Hoy K, Lindblad BE, Terkelson CJ, et al. European soccer injuries: a prospective epidemiologic and socioeconomic study. Am f Sports Med 1992;20:318-22.

4 Sandelin J, Santavirta S, Kiviluoto O. Acute soccer injuries in Finland in 1980. Br F Sports Med 1985;19:30-3.

5 Hawkins RD, Fuller CW. Risk assessment in professional football: an examination of accidents and incidents in the 1994 World Cup finals. Br F Sports Med 1996;30:165-70.

6 Hawkins RD. Injuries in professional football: identification of aetiological factors. $\mathrm{PhD}$ thesis: Loughborough University, 1998.

7 Bird FE, Germain GL. Damage control. New York: American Management Association Incorporated, 1966.

8 Heinrich HW. Industrial accident prevention: a safety management approach. New York: McGraw Hill, 1959.

9 McGregor, JC, Rae A. A review of injuries to professional footballers in a premier football team (1990-93). Scot Med f 1995;40:16-18.

10 Ekstrand J, Gillquist J, Moller M, et al. Incidence of soccer injuries and their relation to training and team success. $\mathrm{Am}$ 7 Sports Med 1983;11:63-7.

11 Schmidt-Olsen S, Bunemann LKH, Lade V, et al. Soccer injuries of youth. Br $\mathcal{F}$ Sports Med 1985;19:161-4.

12 Nielsen AB, Yde J. Epidemiology and traumatology of injuries in soccer. Am f Sports Med 1989;17:803-7.

13 Roaas A, Nilsson S. Major injuries in Norwegian football. $\mathrm{Br}$ f Sports Med 1979;13:3-5.

14 Ekstrand J, Tropp H. The incidence of ankle sprains in soccer. Foot Ankle 1990;11:41-4

15 Jorgensen U. Epidemiology of injuries in typical Scandinavian team sports. Br $\mathcal{F}$ Sports Med 1984;18:59-63.

16 Hoff GL, Martin TA. Outdoor and indoor soccer: injuries among youth soccer. Am F Sports Med 1986;14:231-3.

17 Ekstrand J, Gillquist J. Soccer injuries and their mechanisms: a prospective study. Med Sci Sports Exerc 1983;15:267-70.

18 Health and Safety Executive. The costs of accidents at work. HS(G) $96,1993$.

19 Health and Safety Commission. Health and safety statistics: statistical supplement to the 1996/97 annual report. London: HMSO, 1997

20 Hawkins RD, Fuller CW. A preliminary assessment of professional footballers' awareness of injury prevention strategies. Br F Sports Med 1998;32:140-3.

21 Fuller CW, Hawkins RD. Developing a health surveillance strategy for professional footballers in compliance with UK health and safety legislation. Br F Sports Med 1997;31:14852 .

22 Health and Safety Executive. Human factors in industrial safety. $\mathrm{HS}(\mathrm{G}) 48,1995$.

\section{Commentary}

European football has long traditions and is the most frequently practised sport in the world. However, compared with many other sports, the injury incidence rate of football has been shown to be relatively high, ${ }^{12}$ and therefore all types of studies aimed at injury risk and risk factor assessments are most welcome, not only to increase the general epidemiological knowledge of football injuries but particularly to trigger initiation of attempts at injury prevention.

In this study, the authors analysed the videotaped recordings of 171 televised matches in the 1996 European Championship Finals, 1996/1997 English Premier League, and 1994-1997 English First Division and assessed the injury incidence and frequency rates. The results indicate that, on average, there is about a $12 \%$ chance of any individual professional player receiving an injury that requires medical treatment during a match and that about $15 \%$ of these injuries are so severe that the player will miss at least one game. The authors observed further that $2-3 \%$ of the fouls in a game resulted in a player requiring treatment for injury, but only $15-28 \%$ of all injuries were "intentional" (resulted from foul play). All these findings are important both epidemiologically and for planning prevention strategies. The injury incidence rates were similar for the European Championship, English Premier League, and English First Division, probably because of the similarity between the teams with respect to playing skills and other risk factors for injuries. In the next phase, the authors could assess the injury risk for teams that are clearly at a lower level, as this may produce completely different results. As a working hypothesis, one would expect that players in lower divisions would have a higher injury incidence than the top level players. The next step could be assessment of the exact risk factors, followed by a prevention intervention trial. 


\section{Commentary}

This large and important contribution to the field of football injuries is bound to stimulate further interest and debate. Several of the findings and conclusions are similar to those of a Scottish study ${ }^{1}$ in which the information was gathered in a direct clinical way. More accurate descriptions of the type and sites of injury would have enhanced the value of the paper. The definition of moderate and minor injuries also seems a little vague even though based on "missing the next match". Presumably the authors had no way of obtaining accurate medical information given their method of study. Of some importance to the individual players and their clubs are the longer term effects of injury, which this paper could not address. What it does do, however, is bring attention to the use of video evidence as another way of assessing risk factors in football matches.

JOHN C MCGREGOR

Consultant Plastic Surgeon, St Fohn's Hospital, Livingston, West Lothian

1 McGregor JC, Rae A. A review of injuries to professional footballers in a Premier Football Team (1990-93). Scott Med $\mathcal{F}$ 1995;40:16-18.

\section{Costs of league soccer injuries}

League soccer clubs are businesses and therefore have assets, turnover, operating costs, profits, and shareholders, and the large Premier League Clubs have enormous profits which are returned to the shareholders or reinvested into the company. Most clubs generate no substantial profits and either draw upon shareholders' funds to remain viable or have to generate income by selling their best players in order to pay their debts.

The assets and net worth of such clubs are embodied within the ground, facilities, and the soccer players. The ground is a fixed asset and can only be sold or mortgaged once. It is subject to legislation, such that it has to be serviced with utilities, insured, repaired, and improved regularly. The players, however, only have a book asset value while fit and playing in the first team.

A typical second division league club in the 1997-1998 season had the following figures:
Turnover

Profit

Players and staff wages

Net asset value of playing staff

Pensions

Medical indurance

Other medical costs

Physiotherapists $£ 2$ million, the medical costs of maintaining the principal asset for the players was $£ 50000,2.5 \%$ of the asset value of the playing staff, or less than $4 \%$ of the salary. This may be compared with a typical company car fleet where the annual maintenance insurance costs would be expected to be in the region of $20-30 \%$ of the value, or a typical American football club where $25 \%$ of turnover is spent on fitness, physiotherapy, medical care, and injury prevention. Soccer Clubs in the United Kingdom therefore should, from both a medical and commercial viewpoint, spend much more attention and money on keeping their principal asset, the players, fit and performing.

DAVID P JOHNSON 